\title{
RESSIGNIFICANDO O CUIDADO EM UMA UNIDADE ESPECIALIZADA EM CUIDADOS PALIATIVOS: UMA REALIDADE POSSÍVEL?
}

\author{
Mara Ambrosina de Oliveira Vargas ${ }^{1}$, Janaina Vivan², Rosmari Wittmann Vieira ${ }^{3}$, Joel Rolim Mancia4, Flávia \\ Regina Souza Ramos ${ }^{5}$, Sílvia Ferrazzo ${ }^{6}$, Júlia Valéria de Oliveira Vargas Bitencourt ${ }^{7}$
}

\footnotetext{
${ }^{1}$ Doutora em Filosofia em Enfermagem. Professora do Departamento e Programa de Pós-Graduação em Enfermagem (PEN) da Universidade Federal de Santa Catarina (UFSC). Florianópolis, Santa Catarina, Brasil. E-mail: mara@ccs.ufsc.br

${ }^{2}$ Especialista em Enfermagem em Terapia Intensiva. Porto Alegre, Rio Grande do Sul, Brasil. E-mail: janavivan@yahoo.com.br

${ }^{3}$ Mestre em Bioética e Cuidados Paliativos. Enfermeira do Núcleo de Cuidados Paliativos do Hospital de Clínicas de Porto Alegre. Porto Alegre, Rio Grande do Sul, Brasil. E-mail: rvieira@hcpa.ufrgs.br

${ }^{4}$ Doutor em Enfermagem. Enfermeiro da Prefeitura de Porto Alegre. Porto Alegre, Rio Grande do Sul, Brasil E-mail: joelmancia@ uol.com.br

${ }^{5}$ Doutora em Filosofia em Enfermagem. Professora do Departamento e do PEN/UFSC. Pesquisadora CNPq. Florianópolis, Santa Catarina, Brasil. E-mail: flaviar@ccs.ufsc.br

${ }^{6}$ Mestranda do PEN/UFSC. Florianópolis, Santa Catarina, Brasil. E-mail: silvia.ferrazzo@gmail.com

${ }^{7}$ Mestre em Enfermagem. Professora do Departamento de Enfermagem da Universidade Federal Fronteira Sul. Chapecó, Santa Catarina, Brasil. E-mail: julia.bitencourt@uffs.edu.br.
}

\begin{abstract}
RESUMO: Pesquisa qualitativa, tipo estudo de caso, realizada no Núcleo de Cuidados Paliativos do Hospital de Clínicas de Porto Alegre, Brasil, com os objetivos de conhecer como é prestado o cuidado paliativo ao paciente em uma unidade especializada e como a equipe de enfermagem atua junto ao cuidador(a)/familiar para a continuação das medidas de conforto e alívio da dor. Projeto aprovado pelo Comitê Ética em Pesquisa. Procedeu-se a coleta dos dados por observação do funcionamento da unidade e entrevista semiestruturada com enfermeiras e técnicas de enfermagem. Os resultados são apresentados por meio das temáticas: características do Núcleo de Cuidados Paliativos, sua equipe e a interação inicial desta com o paciente e familiares; e os modos de cuidar, a importância da abordagem da dor e da comunicação. Conclui-se que neste tipo de serviço é ressignificado o papel da tecnologia e dos atributos das relações de cuidado, enfatizando valores éticos, como a confiança e a autonomia.
\end{abstract}

DESCRITORES: Cuidados paliativos. Cuidados de enfermagem. Doente terminal. Autonomia pessoal.

\section{REDEFINING PALLIATIVE CARE AT A SPECIALIZED CARE CENTER: A POSSIBLE REALITY?}

\begin{abstract}
A qualitative research with a case study design was undertaken at the Center for Palliative Care, located within the Hospital de Clinicas de Porto Alegre, Brazil, aimed at knowing how palliative care is provided to patients at a specialized unit and how the nursing team works with the caregiver's family to continue with comfort and pain relief measures. The project received approval from the Ethics and Research Committee. The data were collected through direct observation and semi-structured interviews with nurses and nursing technicians. The results are presented through the themes: characteristics of the Center for Palliative Care, its team and the initial interaction with patients and their families; and the type of care and the importance of pain management and communication. In conclusion, in this type of work, the role of technology and the attributes of care relationships are redefined, and ethical values like trust and autonomy are emphasized.
\end{abstract}

DESCRIPTORS: Palliative care. Nursing care. Terminally ill. Personal autonomy.

\section{REDEFINIENDO EL CUIDADO EN UNA UNIDAD ESPECIALIZADA EN CUIDADOS PALIATIVOS: UNA REALIDAD POSIBLE?}

\begin{abstract}
RESUMEN: Investigación cualitativa tipo estudio de caso, realizada en el Núcleo de Cuidados Paliativos del Hospital de Clínicas de Porto Alegre, Brasil, cuyo objetivo fue conocer los cuidados paliativos proporcionados al paciente en una unidad especializada y ver la actuación del equipo de enfermería con el cuidador(a) familiar en la continuación de las medidas de comodidad y alivio del dolor. Proyecto aprobado por el Comité de Ética y Pesquisa. Se procedió a recolectar los datos mediante la observación directa y entrevistas semi-estructuradas con enfermeras y asistentes de enfermería. Los resultados se presentan a través de los temas: características del Núcleo de Cuidados Paliativos, equipo e interacción inicial con el paciente y familiares; y formas de cuidado, importancia del manejo del dolor y la comunicación. Se concluye que en este servicio es redefinido el papel de la tecnología y los atributos de las relaciones de cuidado, enfatizando los valores éticos como confianza y autonomía.
\end{abstract}

DESCRIPTORES: Cuidados paliativos. Cuidados de enfermería. Enfermo terminal. Autonomía personal. 


\section{INTRODUÇÃO}

Devido à crescente preocupação com a má qualidade de vida vivenciada pelo paciente durante sua doença progressiva, o conceito de Cuidados Paliativos (CPs) passou a fazer parte do cotidiano dos serviços de saúde existentes no Brasil. ${ }^{1}$

Segundo a Organização Mundial da Saúde (OMS), o objetivo dos CPs é a diminuição do sofrimento do paciente terminal e de seus familiares, proporcionando-lhe a melhor qualidade de vida possível e afirmando que o processo de morrer faz parte da vida e não lhe deve ser negado em nenhum momento. ${ }^{2}$

A medicina paliativa não acelera nem retarda o processo de morrer; mas reconhece a morte como natural na vida. Nesta perspectiva, deve-se fornecer apoio e ajuda ao paciente para que ele consiga viver mais ativa e criativamente possível até a hora de sua morte; aos familiares para que eles vivenciem com mais naturalidade e sem tanto sofrimento a doença de seu familiar e o processo de luto. ${ }^{3}$

A filosofia dos CPs é diferente do tratamento curativo. A noção primeira é dar atenção ao doente, e não à doença. Requer, pois, uma abordagem multiprofissional que possa encorajar e ajudar o paciente a aproveitar o melhor que a vida lhe proporciona a cada dia, tratando-lhe de forma respeitosa, respondendo às suas necessidades e aceitando-o com seus valores, crenças e hábitos. ${ }^{4}$

Mas, poucas pessoas estão realmente prontas para as escolhas que talvez precisem ser feitas no final da vida. Escolhas demasiadamente difíceis e que incidem sobre todos os envolvidos, sobre a pessoa doente terminal, os familiares, os entes queridos e os profissionais da saúde. ${ }^{5}$ Nesta perspectiva, entende-se que estabelecer um relacionamento atencioso e competente entre a equipe de enfermagem-paciente-familiares é primordial nos CPs.

A hospitalização destes pacientes se faz necessária quando a família não pode mais cuidar adequadamente do doente, devido à sua dependência total, a qual durará por um período prolongado, ou, na maioria dos casos, quando os familiares não se suportam assistir ao sofrimento de seu ente querido. Paradoxalmente, os hospitais costumam oferecer a prestação de cuidados básicos a esses pacientes e aos seus familiares, não se atentando às suas angústias, ao seu sofrimento. Desconsideram que o paciente está à procura de uma boa morte, com dignidade, respeito e sem dor. Logo, devido à necessidade de um cuidado diferenciado, foram criados, em todo o mundo, locais específicos que acolhem esses pacientes. ${ }^{6}$

Em suma, entende-se que, embora tenha havido enorme expansão dos programas relacionados aos CPs em unidades hospitalares, nem todos os hospitais têm unidades especializadas nestes cuidados. Além disso, é pressuposto que os profissionais de saúde, de modo geral, desconhecem e não aplicam essa filosofia de trabalho e que as instituições de saúde não constituem estrutura física para a inserção de um Núcleo de Cuidados Paliativos (NCP). Por este motivo, esse estudo objetiva conhecer como são prestados os CPs ao paciente em uma unidade especializada nestes cuidados, e como a equipe de enfermagem atua junto ao cuidador(a)/familiar, no sentido de instituir medidas de conforto e alívio da dor.

\section{METODOLOGIA}

Pesquisa qualitativa, sendo um estudo de caso único institucional, realizada no NCP do Hospital de Clínicas de Porto Alegre (HCPA), em 2009. Trata-se de um hospital público, universitário, que oferece atenção integral à saúde, participa ativamente de pesquisas e ações de ensino e é considerado referência em CP no Brasil. Participaram desta pesquisa todas as cinco enfermeiras do NCP e cinco técnicas de enfermagem, que atuavam no atendimento a pacientes em fase terminal, selecionadas por sorteio, uma de cada turno de trabalho (manhã, tarde, noite 1 , noite 2 e noite 3 ). Os dados foram coletados após a aprovação pelo Comitê de Ética em Pesquisa da instituição (n. 09-147) e assinatura pelos participantes do Termo de Consentimento Livre e Esclarecido. Os sujeitos da pesquisa participaram de entrevista semiestruturada, gravada e, posteriormente, transcrita na íntegra e agrupada por categorias. As entrevistas ocorreram numa sala privativa dentro do $\mathrm{NCP}$, em horário de trabalho dos participantes da pesquisa. Além da entrevista, foi realizada observação direta a fim de registrar o modo como o NCP funciona, sua rotina de trabalho, as condições de ambiente que são disponibilizadas aos pacientes e seus familiares, bem como aos profissionais da área da enfermagem. Durante a pesquisa, foram atendidas as exigências das diretrizes e normas brasileiras regulamentadoras de pesquisa envolvendo seres humanos (Resolução CNS 196/96). ${ }^{7}$ A análise das informações seguiu a técnica de análise temática, 
abrangendo as fases: pré-analítica, exploração do material e interpretação dos resultados. Ainda, destaca-se que, por se tratar de um estudo de caso, procurou-se preservar a totalidade da unidade social, ou seja, além das temáticas que emergiram registrou-se de modo amplo o contexto estrutural e social do NCP.

\section{RESULTADOS E DISCUSSÃO}

Os resultados são apresentados em dois temas principais. O primeiro tema destaca algumas características do NCP, cenário do estudo, além de apresentar sua equipe e os primeiros momentos de interação desta com o paciente e familiares. No segundo tema o foco é sobre os modos de cuidar na unidade de $\mathrm{CP}$, em que se destaca a abordagem da dor, a importância da comunicação e da confiança, além da autonomia como valor fundamental deste cuidado.

\section{Um lugar especial para pessoas em situação especial}

A criação de uma unidade especialmente organizada e preparada para receber pacientes em fase terminal já indica uma lógica diferente daquela que ordena os demais espaços hospitalares, das especialidades médicas e da disponibilidade tecnológica. A lógica se desloca da cura para o objetivo do conforto e para a qualidade das relações estabelecidas entre a equipe e pacientefamília. Esta lógica deve se expressar em todas as configurações estruturais, organizacionais e, destacadamente, no preparo da equipe. Por isso, é importante reconhecer a unidade estudada e como ocorre a entrada, ou a acolhida, dos pacientes neste espaço.

O NCP possui seis leitos, sendo um quarto composto por dois leitos e os demais com leito individual. Cada quarto possui: ar condicionado, televisão, armário, banheiro, mural (criado com o objetivo de os familiares e amigos deixarem suas mensagens, fotos ou, até mesmo para o paciente colocar poemas, imagens ou o que desejar), poltrona com lençol, cobertor, fronha e travesseiro para os familiares, os quais são trocados uma vez na semana. No NCP é solicitada a presença de um familiar $24 \mathrm{~h}$ por dia. Ainda, no quarto consta um frigobar para o familiar trazer alimentos de que ele e o paciente gostem, mesmo que estes alimentos não façam parte da dieta do paciente e/ou do hospital.
Para todos os familiares é fornecido almoço. $\mathrm{E}$, nas situações em que o paciente é proveniente de uma cidade longíqua ou que não possui condições financeiras para comprar alimentos, a enfermeira procura conseguir todas as refeições aos familiares.

O NCP dispõe de uma sala de estar onde os familiares/cuidadores e o próprio paciente, caso consiga sair do leito, poderão receber visitas e relaxar. Nesta sala, todas as quartas-feiras, a equipe multiprofissional realiza encontros com os familiares/cuidadores dos pacientes, para compartilharem experiências e falar sobre suas angústias. Este momento é considerado de escuta.

Acolhimento para ofamiliar, onde ele começa a se sentir também cuidado, inserido no cuidado, no contexto de cuidado, porque nos outros andares ele é mais um a ajudar a cuidar do paciente, é mais um a ajudar a virar o paciente de lado, e não mais um a ser cuidado pela equipe. É uma hora em que cuidamos especificadamente do cuidador (I 5).

No NCP, é consentido aos visitantes permanecerem até às $22 \mathrm{~h}$; a visita de crianças é liberada, desde que elas estejam acompanhadas por um adulto e que permaneçam por um curto período de tempo no quarto do paciente. Cada familiar recebe um cartão de visitas, que é apresentado na portaria, para que a pessoa possa se dirigir até o NCP. São permitidos também cultos de diferentes crenças.

Respeitamos muito a vontade do paciente, as crenças dele, então, se querem fazer um culto diferente do que a gente está acostumada, com gritos e tal, não trazendo animais mortos ou vivos, não fazendo sacrifícios, o resto tudo está liberado. Também é uma forma de acolher, de humanizar o atendimento (I 5).

Pesquisas recentes indicaram que crenças religiosas ou espirituais influenciam as decisões de tratamento em situações de severidade e de terminalidade. A espiritualidade é uma expressão de como as pessoas se relacionam com um todo maior - algo maior do que eles mesmos - e como eles encontram significado no meio de seu sofrimento. ${ }^{5}$

Em CP, a espiritualidade aparece como meio de enfrentamento e é muitas vezes vista como sinônimo de religião, mas é, naturalmente, um conceito mais amplo. O elemento religioso pode ser um componente da espiritualidade. ${ }^{8}$

O NCP possui ainda um posto de enfermagem, onde estão os prontuários dos pacientes, as medicações e materiais. A equipe multiprofis- 
sional é composta por: enfermeiras, técnicas(os) e auxiliares de enfermagem, médicos da equipe de medicina interna, psicólogos, assistente social, entre outros. Cada técnico(a) ou auxiliar permanece com três pacientes, já que todos necessitam de muita atenção.

A equipe de saúde deve ser composta por profissionais de diferentes áreas de formação, que possam promover uma assistência completa ao paciente e seus familiares. Estes profissionais devem respeitar as diferenças, procurando não julgar valores, estar dispostos a esclarecer possibilidades para o paciente e seus familiares enfrentarem este momento de suas vidas, amenizando o sofrimento de todos, inclusive da própria equipe. ${ }^{6}$

Quando há solicitação, advindas de outras unidades do hospital, para efetivar tranferência do paciente para o NCP, a enfermeira do Núcleo vai ao encontro deste paciente e de seus respectivos familiares para avaliação. Nesta avaliação prévia, um dos requisitos para internação no NCP é verificar se o paciente está lúcido e orientado para poder aproveitar o restante de seus dias de vida.

A gente vai lá, avalia o paciente, conversa com o paciente e com a família, e aí a gente já começa a fazer o vinculo. É quando a gente trabalha muito com o sonho, com alternativas de vida, com o que eles acreditam, com o que eles sabem da patologia, porque falar sobre isso é uma coisa que pouca gente fala, e eles precisam ouvir e saber que podem contar com alguém para conversar sobre isso (I 5).

Nesse primeiro acolhimento, já fazemos um planejamento com ele, de como ele vai continuar sendo cuidado, e já começamos a trabalhar a confiança. Dizemos para ele que vamos levá-lo para outra área, então, temos que agregar valores para eles (I 6).

Nessa entrevista, os familiares são informados que, no NCP, não são realizadas algumas intervenções no paciente, como, por exemplo, chamar o Centro de Terapia Intensiva para reanimá-lo. É sinalizado que um dos objetivos do NCP é o alívio dos sintomas. Também, são planejadas, com os pacientes, maneiras de fornecer qualidade de vida, para que seus últimos dias não se convertam em dias perdidos.

Para realizar um bom cuidado, a equipe de saúde necessita conhecer as técnicas, prestar informações, ter consideração para com os outros, respeito, postura e expressar interesse pelo que é dito pelo paciente e familiar. Não é suficiente deixar a família acompanhar o paciente, mas é necessário questioná-la sobre suas dúvidas, compreender suas emoções, suas reações e seu comportamento diante do processo de morte, pois cuidar requer perceber o outro como realmente é, sua fala, seus gestos, suas limitações. ${ }^{9}$

Chegando ao NCP, é explicada a rotina ao paciente e aos seus familiares, e são mostradas as instalações já descritas anteriormente. Após as informações, são iniciados os cuidados específicos para aliviar os sinais e sintomas e controlar a dor do paciente. Contudo, neste contexto de cuidado, todos os profissionais são cuidadores. O pressuposto é que ninguém consegue cuidar sozinho do paciente.

O médico tem papel de cuidador, pois já não existe um cuidador principal. Ele passa a dividir conosco, ele tem um vínculo anterior, então, ele passa segurança para o paciente, e nós vamos dar toda a estrutura para que tudo aquilo que for planejado seja cumprido (I 6).

Assim que em que as enfermeiras evidenciam a necessidade de um cuidado mais específico, utilizam os procedimentos operacionais padrão do hospital, adaptando-os à realidade do momento. Em casos em que pacientes vão para casa com sonda e/ ou traqueostomia, é realizada capacitação dos familiares para desenvolverem os cuidados necessários.

Nós já temos vários adaptados. Transformamos os termos técnicos em mais acessíveis. No primeiro momento, é dado por escrito para o cuidador; num segundo momento, a enfermeira vai lá e treina vários dias até que o cuidador consiga fazer o cuidado (I 3).

Ele só vai quando o médico já deu alta clínica e o paciente está estabilizado e, às vezes, os pacientes ficam mais dois ou três dias porque os familiares não estão prontos para ir embora, e, quando eles vão embora, aí a gente fica monitorando por $24 \mathrm{~h}$. Eles podem ligar para nós para falar com a enfermeira e para retirar dúvidas do cuidador sobre o que não entendeu no diagnóstico, sinais e sintomas, algum manejo de prescrição que eles têm. Então, isso evita que eles retornem mais seguido, sem necessidade (I 6).

Todos os profissionais que atuam no NCP recebem treinamento antes de começar a trabalhar. Uma vez por semana, eles se reúnem para conversar, para discutir as atitudes tomadas em relação aos cuidados com o paciente e também para compreender o paciente como um todo.

Nós tivemos alguns encontros, alguns cursos antes de abrir o paliativo. A gente leu bastante, teve esclarecimento de que a morfina é só mais uma medicação, então, tem algumas coisas que foram esclarecidas; 
mas tem o outro lado, o lado da espiritualidade, que éo humano que entra ali, é o carro chefe (I 1).

A gente tem, uma vez por semana, uma reunião até para a gente tentar entender o todo do paciente, porque o paciente é um todo. Ele não está mais com dor à noite porque ele está pensando na sua morte, ele está com dor porque hoje de manhã ele viu um filho ou ele quer ver o filho. Então, tem uma série de coisas que a gente tem que entender porque a dor não é tratada isolada, como física, mas o que naquele momento está perturbando ele para que ele possa e nós possamos intervir (I 6).

Uma estratégia para qualificar o cuidado prestado, como no caso das reuniões de equipe, cumpre também o papel de apoio aos profissionais, tornando-se um espaço privilegiado de formação permanente. Neste sentido, os participantes ressaltam as dificuldades pessoais e grupais a serem superadas por meio do compartilhamento dos desafios, tanto técnicos como afetivos e da própria reconfiguração de identidades profissionais. Profissionais formados para serem agentes de cura e metas terapêuticas pré-determinadas, agora precisam antever novos objetivos e se cercar de novos instrumentais.

No início, foi pesado. Não digo que agora não seja, mas no início, quando a gente perdia um paciente, ficava muito mal toda a equipe. Acho que a gente foi educando um pouco o nosso organismo quanto a isso, mas acostumar com a morte não, nunca, é difícil, não tem como. Sentimos muito a perda, porque nos outros lugares em que a gente trabalhou a gente trata o paciente para melhorar, ir embora e ficar bem, e esse paciente não, esse paciente às vezes vai para casa, mas nem sempre fica bem, quase sempre não fica bem (I 2).

Nessa semana, tivemos uma polêmica. Um paciente teve um diagnóstico recente, e a família não aceitava que não tivesse mais nada para fazer. Fizemos reuniões para rever por que não estavam sendo tomadas determinadas atitudes, determinadas intervenções, $e$ foi um trabalho muito bom porque a gente viu que, em pouco tempo, conseguimos fazer com que as pessoas aceitassem de uma maneira mais natural a situação da morte, já que é uma questão nada fácil (I 3).

Alguns provedores de cuidados de saúde - médicos, enfermeiros, assistentes sociais, farmacêuticos, clero e outros - aprenderam a cuidar bem, de um modo especial. Mas, todos os prestadores de cuidados de saúde devem saber como prestar bons $\mathrm{CP},{ }^{5}$ o que, segundo estudiosos sugerem, pode reduzir significativamente o tempo de internação hospitalar. ${ }^{10}$
Especificamente em relação à enfermagem, a educação em $\mathrm{CP}$ pode reduzir significativamente o sofrimento e fornecer conforto e dignidade a pacientes que estão morrendo e suas famílias. Educar não só os enfermeiros, mas toda a equipe de enfermagem é fundamental para proporcionar bons cuidados. ${ }^{11}$

\section{Modos de cuidar na Unidade de Cuidados Paliativos}

Muitos doentes sofrem, desnecessariamente, quando não recebem a atenção necessária e adequada para os sintomas que acompanham sua doença ou compreensão de suas angústias, sofrimentos e necessidades. O profissional que trabalha no NCP valoriza a sua capacidade de indagar:

Perguntamos o que mais está incomodando, a comida, saber o que pode e o que não pode. Aqui todas as rotinas são quebradas, e isso tem um impacto positivo, e a gente avalia o que é benefício e ganho. Mas se o paciente está em NPO e quiser comer um sorvete, mas ele está com náusea e vômito, a gente medica para náusea e vômito e o deixamos comer o sorvetinho dele, nem que depois ele vomite, mas ele comeu (I 6).

Perguntam e eles (os pacientes) relatam a dor como um dos sintomas físicos mais frequentes. A dor é considerada uma experiência desagradável, sensitiva ou emocional, um sofrimento estressante que causa uma importante redução na qualidade de vida dos pacientes, quando o sintoma não é bem avaliado e controlado. A incapacidade de comunicar a dor não equivale à ausência desta, e os objetivos dos CP são eliminar por completo a dor e os sintomas da doença quando possível ou diminuí-los a níveis que o paciente possa tolerar quando não puderem ser completamente aliviados. ${ }^{12}$

A dor aqui é uma filosofia, a dor é zero, e quando eles chegam com dor a gente tem que controlar em quatro, cinco, seis, sete horas, supor naquela manhã, já. Então, de dor ninguém sofre nesta unidade (I 6).

Devido ao tempo que eles precisam a mais e que eu também preciso com eles, porque se eu vou agora lá e ofereço, pergunto se ele está com dor, ele pode me dizer que não, mas eu converso cinco minutos com ele e eu descubro que ele está com dor ou é outra coisa, talvez não seja dor, talvez seja só mudar o decúbito e já vai melhorar. Para mim, o tempo é imprescindível, é fundamental (I 4).

A dor está entre os sintomas mais comuns e angustiantes encontrados pelos pacientes com 
câncer avançado e outras doenças terminais. $\mathrm{O}$ desafio relacionado à dor é obter alívio eficaz com mínimos efeitos colaterais e fornecer esse serviço para todos os pacientes que necessitam destas intervenções. ${ }^{13}$ Nos Estados Unidos, um estudo mostrou que nos últimos três dias de vida, dois quintos de todos os pacientes em todas as categorias de doenças incluídas apresentavam fortes dores. ${ }^{10}$

A enfermeira deve ensinar o(a) cuidador(a)/ familiar sobre a continuação das medidas de conforto e alívio da dor. Deve oferecer-lhes módulos educativos sobre os cuidados que se estenderão ao domicílio do paciente, pois o processo de orientação contínua é de absoluta importância para uma boa provisão de CP no domicílio. ${ }^{14}$

No NCP, a equipe de enfermagem trabalha com os cuidadores/familiares os cuidados necessários em relação a sondas, traqueostomia, pele - para prevenir úlceras de decúbito -, medicações. A noção primeira é que os cuidadores/familiares participem do cuidado e, caso o paciente tenha alta, eles possam prestar os cuidados com maior segurança.

Evidencia-se a importância do papel educador da equipe. Novas especializações nas áreas médicas, de enfermagem e assistência social baseadas em CP surgiram para atender as necessidades de pacientes com graves enfermidades e seus familiares. ${ }^{15}$

Fazemos planilhas de hora em hora... com os horários bem certinhos do que e quanto ele vai receber, tabela mostrando cada medicação. É para uma pessoa que não entende nada conseguir entender, se precisar desenhar, a gente desenha; se precisar colar o rótulo para ele saber qual é qual, a gente faz. Para cada caso é diferente. Como faz o curativo, como muda de decúbito, de quanto em quanto tempo muda de decúbito, como é que previne para não fazer feridinha no bumbum. A gente trabalha cada paciente com a sua necessidade e com a família dele, com os principais cuidadores ou com o principal cuidador. Às vezes, leva um tempo enorme porque tu tens que organizar cada um deles, porque a interpretação de cada umé diferente (I 5).

Também já preparamos o familiar que poderá ocorrer alguma urgência, como sangramento, uma dispnéia mais importante, que não é para ele se apavorar. É só ligar para nós, e damos as coordenadas, e ele vem para a emergência e da emergência sobe para nós de novo (I 6).

Tu tens que trabalhar as mesmas angústias, as mesmas dificuldades, os mesmos questionamentos [do paciente e da família] quando o paciente não quer a sonda e a família quer, tem que trabalhar a ansiedade, o medo dos familiares, para permitir que aquele planejamen to terapêutico com o paciente seja cumprido e que não sejamos nós, a equipe, a boicotar (I 6).

A filosofia de CP traz consigo o ato de proteger, amparar, cobrir, abrigar, ou seja, cuidar quando a cura de determinada doença não é mais possível. É esperado que profissionais capacitados em CP valorizem a dimensão emocional do cuidado, desenvolvendo habilidades que lhes permitam acessá-la e atender demandas específicas para cada indivíduo. ${ }^{16}$

A relação de confiança entre o enfermeiro e o paciente deve ser considerada essencial na prática de enfermagem. Nesta direção, durante sua formação, o enfermeiro é ensinado a ser genuíno, compassivo, sem julgamento e honesto, atributos que são chaves para ser confiável em qualquer relacionamento. ${ }^{17}$

Essa é uma unidade em que os pacientes não vão para a CTI, então, quando eles estão na fase bem agônica, dispnéicos, e a gente vai fazendo morfina pra aliviar o máximo, coloca máscara de Venturi. Desde o primeiro, já não sei quantos casos passaram por aqui, nenhum familiar solicitou ir para a CTI - sinal de que não é tecnologia que eles precisam naquele momento. É uma unidade de pequena-média complexidade, mas é uma unidade de muito toque, de estar do lado, é muita presença, muito silêncio também, chorar quando dá vontade [...]. As nossas emoções também podem ser demonstradas, desde que seja num nivel de controle (I 6).

Muitas vezes, o paciente morreu e, no mesmo dia em que eles enterram, à noite já ligam para nós. A gente vê que tem um pacto conosco, então a gente fica tranquilo porque está fazendo o enfoque terapêutico nele e está atingindo o familiar, e que não foi só na hora do óbito, mas acaba refletindo no amanhã, no depois de amanhã. Temos até um conceito, os familiares aqui definiram Cuidados Especiais, e a gente já está definindo que existe vida depois da morte para os familiares. Eles conseguem já respirar dentro da sua dor (I 6).

Comunicar-se adequadamente com o paciente e seus familiares é uma medida eficaz para o cuidado prestado nos momentos finais, diminuindo as angústias, o estresse e a ansiedade ao compartilhar o sofrimento com a equipe. Para que sejamos bons profissionais, devemos olhar atentivamente o outro, prestar atenção em seus gestos, em sua fala, em suas atitudes. Com isso, garantimos que nos importamos com o que eles 
estão vivenciando e sentindo, e não somente com o alívio dos sintomas de sua patologia. ${ }^{18}$

Ainda, é pertinente ressaltar que neste modo de cuidar a autodeterminação é a base para a suspensão de esforços terapêuticos para os usuários dos serviços de saúde. Esses esforços são compreendidos como não iniciar uma terapia ou suspendê-la uma vez iniciada, não ressuscitar nos casos de parada cardiorrespiratória, não submeter o doente à ventilação mecânica, alimentação e hidratação artificial contra a sua vontade, devendo o médico e demais profissionais respeitar a autonomia do usuário, inclusive deixando que a morte ocorra no local, no tempo e em companhia de quem o doente quiser. ${ }^{19}$

Tivemos uma paciente que tinha um tumor de esôfago, que tinha indicação de traqueostomia, e ela não queria colocar, o médico conversou, disse: 'olha, a senhora vai morrer sufocada porque o seu tumor está crescendo muito', e realmente ela estava muito dispnéica para falar, ela era muito falante e ela estava bem disfuncionada porque não entrava a quantidade de ar necessária e ela disse: 'eu prefiro morrer com falta de ar a fazer uma traqueostomia, e eu sei que eu vou morrer igual, então me deixem morrer com o meu pescoço inteiro'. A família inteira concordou porque ela era completamente lúcida, e essa paciente acabou não morrendo sufocada, mas ela teve uma hemorragia devido ao tumor e não tinha como estancar, ela morreu vomitando, abanando e sorrindo para nós. Foi uma morte muito estranha, mas ela morreu feliz, foi uma morte horrorosa, de repente, para quem olha, mas para ela não foi, ela morreu com o pescoço inteiro e feliz (I 5).

$\mathrm{O}$ respeito à autonomia do paciente leva em consideração a maneira própria de o paciente apreender o mundo, de fazer suas escolhas fundamentadas em valores próprios, agindo de acordo com seus princípios, suas crenças e sua visão do mundo. Saber ouvir é mais que uma qualidade, é uma necessidade que favorece a relação entre o profissional e o paciente, reforçando a confiança entre eles, permitindo acompanhar o paciente em sua trajetória de decisão, ouvindo-o, esclarecendo-o e, acima de tudo, respeitando-o. ${ }^{20}$

Neste contexto, acompanhar significa oferecer companhia durante um período de incertezas e sofrimento em que, muitas vezes, o profissional não pode aliviar a carga do paciente, mas seguirá ao seu lado até o fim da jornada. ${ }^{16} \mathrm{~A}$ conduta de amparo do profissional a um paciente no exato momento de morte o conforta frente a situações chocantes mas, mesmo os profissionais que seguem a filosofia paliativista, demonstram fragilidade na competência ao enfrentamento da morte, sendo pertinente o dicernimento entre respeitar a vontade do doente e nada fazer para retardar sua morte, em contraponto ao foco da formação profissional que costuma ser na e pela cura e saúde humana.

Para ser prestado um cuidado eficiente ao paciente terminal, a equipe deve caminhar lado a lado com ele, ajudando-o em suas decisões, nunca julgando ou decidindo por ele. Conforme relatos da equipe de enfermagem no NCP, esta autonomia é bem desenvolvida na prática, fazendo com que o paciente possua todo o controle em relação à sua vida e ao seu tratamento.

Os cuidados prestados ao paciente dentro do NCP vão além do conforto físico, do alívio da dor. Estes cuidados envolvem o toque, o ouvir, o permanecer em silêncio somente segurando a mão, dando um apoio moral, carinho. Tais cuidados são fundamentais nesta fase final ao paciente e aos seus familiares e são enfatizados por diferentes estudiosos.

\section{CONSIDERAÇÕES FINAIS}

O presente estudo de caso foi realizado em uma Unidade de Cuidados Paliativos, possui uma adequada estrutura física e humana para acolher os pacientes que possuem doenças incuráveis e terminais e seus familiares. Sabe-se que este tipo de serviço é uma necessidade e uma realidade concreta, que vem desenvolvendo-se cada vez mais, principalmente na direção da equipe profissional e das instituições de saúde que aprenderam a lidar com os pacientes acometidos pelo câncer e com uma expectativa de vida limitada.

A entrada ou transferência do paciente para um NCP representa uma mudança radical no projeto terapêutico, daí a importância desta mudança ser desejada e compreendida pelo paciente e sua família. Os médicos que já prestam atendimento a este paciente em outras unidades permanecem na equipe de cuidado, mantendo a relação já estabelecida e evitando sentimentos de abandono ou insegurança diante do novo. A equipe de enfermagem dedica atenção ao paciente e aos seus familiares e assim, ganham importância os atos de ouvir, conversar, apoiar, mesmo que expresso em silêncio e toque. É uma unidade em que são re-significadas ações algumas vezes desvalorizadas, como o toque, o estar presente, o esclarecer dúvidas em relação à medicação, cuidados, patologia, sinais e sintomas que o paciente possui ou 
poderá apresentar. Na verdade, é ressignificado o papel da tecnologia e dos atributos das relações de cuidado, enfatizando valores éticos, como a confiança e a autonomia.

Todos os cuidadores/familiares são treinados pela equipe de enfermagem em relação aos cuidados com o paciente. Eles recebem treinamento e explicações, em relação a sinais e sintomas que o paciente possa vir a apresentar e qual a melhor maneira de prestar o cuidado, reconhecendo que esta "melhor maneira" sempre é individualizada e negociada. A equipe de enfermagem tranquiliza o cuidador/familiar, enfatizando que sempre que ele tiver dúvida ou dificuldade poderá procurar o NCP. Os familiares e pacientes precisam confiar que, no momento em que chegarem à emergência do hospital, o NCP será acionado para buscá-los, pois agora eles fazem parte desta nova família. A equipe está sempre enfatizando ao cuidador que agora ele não é mais um a cuidar do paciente, e sim mais um a ser cuidado por todos em suas necessidades, mais um a ser ouvido.

Apesar dos benefícios produzidos por estas formas de cuidar, ainda há poucos locais especializados, bem estruturados e com uma equipe tão bem qualificada para atender o paciente em cuidados paliativos. Considera-se que neste local, situado em um hospital, tenha se constituido um lugar possível em que uma pessoa consiga terminar bem sua última etapa de vida.

Ao final do estudo, foi possível constatar na prática que é possível oferecer serviços qualificados em uma unidade de cuidados paliativos que, com dedicação, atenção e carinho, proporcione aos pacientes uma terminalidade com qualidade de vida e, consequentemente, uma morte mais digna.

\section{REFERÊNCIAS}

1. Vieira RW. Bioética, cuidados paliativos e qualidade de vida: a importância do processo de tomada de decisão [dissertação]. Porto Alegre (RS): Universidade Federal do Rio Grande do Sul, Programa de Pós-Graduação em Medicina; 2010.

2. Floriani CA, Schramm FR. Cuidados paliativos: interfaces, conflitos e necessidades. Ciênc Saúde Coletiva. 2008 Dez; 13(2):2123-32.

3. Pessini L, Bertachini L. Humanização e cuidados paliativos. $2^{\mathrm{a}}$ ed. São Paulo (SP): Loyola; 2004.

4. Alvarenga RE. Cuidados paliativos domiciliares: percepções do paciente oncológico e de seu cuidador. Porto Alegre (RS): Moriá Editora Ltda; 2005.
5. Last Acts National Program Office. Means to a better end: a report on dying in American today. Washington (US): Last Acts; 2002.

6. Kruse MHL, Vieira RW, Ambrosini L, Niemeyer, F, Silva FP. Cuidados paliativos: uma experiência. Rev HCPA. 2007; 27(2):49-52.

7. Ministério da Saúde (BR). Manual operacional para comitês de ética em pesquisa. Brasília (DF): MS; 2007.

8. Irreland J. Palliative care: a case study and reflections on some spiritual issues. BJNursing [online]. 2010 [acesso 2011 Nov 30]; 19(4):237-40. Disponível em: http://cat.inist. fr $/$ ?aModele $=$ afficheN\&cpsidt $=22455307$

9. Inaba LC, Silva MJP, Telles SCR. Paciente crítico e comunicação: visão de familiares sobre sua adequação pela equipe de enfermagem. Rev Esc Enferm USP. 2005 Dez; 39(4):423-9.

10. Higginson IJ, Finlay I, Goodwin DM, Cook AM, Hood K, Edwards AGK, et al. Do hospitalbased palliative teams improve care for patients or families at the end of life? J Pain Symptom Manage [online]. 2002 Feb [acessed 2012 Jan 30]; 23(2):96-106. Available: http://download.journals. elsevierhealth.com/pdfs/journals/0885-3924/ PIIS0885392401004067.pdf

11. Kelly K, Thrane S, Virani R, Malloy P, Ferrell B. Expanding palliative care nursing education in California: the ELNEC geriatric project. Int J Palliat Med [online]. 2011 [acessed 2012 Jan 10]; 17(4):18894. Available: http://ukpmc.ac.uk/abstract/ MED/21537321

12. Peres MFP, Arantes ACLQ, Lessa PS, Caous CA. A importância da integração espiritual e da religiosidade no manejo da dor e dos cuidados paliativos. Rev Psiquiatr Clín. 2007; 34(Supl 1):82-7.

13. Caraceni A, Cherny N, Fainsinger R, Kaasa S, Poulain P, Radbruch L, et al. Pain measurement tools and methods in clinical research in palliative care: recommendations of an expert working group of the European Association of Palliative Care. J Pain Symptom Manage [online]. 2002 [acessed 2012 Jan 30]; 23(3):239-55. Available: http:// download.journals.elsevierhealth.com/pdfs/ journals/0885-3924/PIIS0885392401004092.pdf

14. Araújo LZS, Araújo CZS, Souto AKBA, Oliveira MS. Cuidador principal de paciente oncológico fora de possibilidade de cura, repercussões deste encargo. Rev Bras Enferm 2009 Fev; 62(1):32-7.

15. Weissman DE, Meier DE. Identifying patients in need of a palliative care assessment in the hospital setting - a consensus report from the center to advance palliative care. J Palliat Med [online]. 2011 Jan [acessed 2012 Jan 08]; 14(1):17-23. Available: http://online.liebertpub.com/doi/abs/10.1089/ jpm.2010.0347

16. Araújo MMT, Silva MJP. O conhecimento de 
estratégias de comunicação no atendimento à dimensão emocional em cuidados paliativos. Texto Contexto Enferm 2012 Jan-Mar; 21(1):121-9.

17. Becker AL. Ethical considerations of teaching spirituality in the academy. Nurs Ethics [online]. 2009 [acessed 2012 Jan 08]; 16(6):697-706. Available: http://nej.sagepub.com/content/16/6/697.short

18. Araújo MMT, Silva MJP. A comunicação com o paciente sob cuidados paliativos: valorizando a alegria e o otimismo. Rev Esc Enferm USP. 2007 Dez; 41(4):668-74.

19. Ribeiro DC. Autonomia: viver a própria vida e morrer a própria morte. Cad Saúde Pública 2006 Ago; 22(8):1749-54.

20. Vicentin A, Labronici L, Lenardt MH. Autonomia do paciente idoso com câncer: o direito de saber o diagnóstico. Acta Paul Enferm. 2007 Out-Dez; 20(4):509-13

Correspondência: Mara Ambrosina de Oliveira Vargas

E-mail: mara@ccs.ufsc.br 